\title{
ANALISIS MODEL PENGARUH GOAL ORIENTATION, GENERAL SELF - EFFICACY DAN JENIS KELAMIN TERHADAP SELF-REGULATED LEARNING DALAM PEMBELAJARAN JARAK JAUH
}

\author{
Santi Yudhistira $^{1}$, Deasyanti ${ }^{2}$, Fellianti Muzdalifah ${ }^{3}$
}

\author{
${ }^{1}$ Fakultas Pendidikan Psikologi, Universitas Negeri Jakarta ${ }^{1}$ \\ Email: santiyudhistira@unj.ac.id \\ ${ }^{2}$ Fakultas Pendidikan Psikologi, Universitas Negeri Jakarta \\ Email: deasyanti@unj.ac.id \\ ${ }^{3}$ Fakultas Pendidikan Psikologi, Universitas Negeri Jakarta \\ Email:f_muzdalifah@unj.ac.id
}

\begin{abstract}
Since COVID-19's entry into Indonesia in early March, 2020, the government has determined all educational institutions to carry out learning activities using the Distance Education method. The method changes are so fast that students as students who use this method do not have much time to adjust and meet various obstacles. This study aims to see how self-efficacy and goal orientation influences students self-regulated learning while carrying out distance education. This study also wants to look at differences in self-regulated learning between male and female students. This research uses quantitative methods. Respondents in this study were 319 students at a university in Jakarta who were carrying out learning activities with distance education methods. The instrument used is General Self-Efficacy Scale (Schwarzer \& Jerusalem, 1995), 2x2 Achievement Goal Orientation Framework (Elliot \& McGregor, 2001), and Metacognitive Self-Regulation dalam Motivated Strategies Learning Questionaire (MSLQ). The validity of the measuring instrument was carried out using the Confirmatory Factor Analysis (CFA) method and hypothesis testing using path analysis processed through Mplus software version 7.11. The results of the path analysis test found that the model tested fit with the chi-square index $=2.39, d f=1, p$-value $=0.25>0.05$ ), and RMSEA $=0.067$. The final results of the study showed that self-efficacy, goal orientation, and gender had an effect of $19.7 \%$ on student self-regulated learning.
\end{abstract}

Keywords: general self-efficacy, goal orientation, self-regulated learning, gender, distance education.

\begin{abstract}
ABSTRAK
Sejak masuknya COVID-19 ke Indonesia awal Maret tahun 2020, pemerintah menetapkan seluruh institusi pendidikan untuk melaksanakan kegiatan belajar dengan metode Pembelajaran Jarak Jauh (PJJ). Perubahan metode yang begitu cepat menyebabkan mahasiswa sebagai peserta didik yang menggunakan metode ini tidak memiliki banyak waktu untuk menyesuaikan diri dan menemui berbagai kendala. Penelitian ini bertujuan untuk melihat bagaimana pengaruh keyakinan diri (self-efficacy) dan penetapan tujuan belajar (goal orientation) terhadap strategi regulasi dan pengelolaan aktivitas belajar (self-regulated learning) pada mahasiswa dengan metode PJJ. Penelitian ini juga ingin melihat self-regulated learning pada mahasiswa laki-laki dan perempuan. Penelitian ini menggunakan metode kuantitatif. Responden dalam penelitian ini adalah 319 mahasiswa disalah satu universitas di Jakarta yang sedang melaksanakan kegiatan belajar dengan metode PJJ. Alat ukur yang digunakan yaitu General Self-Efficacy Scale (Schwarzer \& Jerusalem, 1995), 2x2 Achievement Goal Orientation Framework (Elliot \& McGregor, 2001), dan Metacognitive Self-Regulation dalam Motivated Strategies Learning Questionaire (MSLQ). Validitas alat ukur dilakukan dengan metode Confirmatory Factor Analysis (CFA) dan pengujian hipotesis menggunakan Path Analysis yang diolah melalui software Mplus versi 7.11. Hasil uji Path Analysis diketehui model yang diuji fit dengan indeks chi-square $=2,39, d f=1, p$-value $=0,25>0,05)$, dan $R M S E A=0,067$. Hasil akhir penelitian menunjukkan self-efficacy, goal orientation, dan jenis kelamin memberikan pengaruh sebesar 19,7\% terhadap self-regulated learning pada mahasiswa.
\end{abstract}

Kata Kunci: general self-efficacy, goal orientation, self-regulated learning, jenis kelamin, PJJ 


\section{PENDAHULUAN}

\section{Latar Belakang}

Sejak diumumkannya kasus pertama Coronavirus Disease (COVID-19) pada awal Maret 2020 oleh pemerintah, penyelenggaraan pendidikan di Indonesia mengalami berbagai perubahan. Melalui Surat Edaran Kementerian Pendidikan dan Kebudayaan Nomor 04 Tahun 2020, pemerintah menetapkan kebijakan bahwa selama masa penanganan Covid 19, pendidikan diselenggarakan dari rumah atau disebut dengan Belajar Dari Rumah (BDR). Kemendikbud kemudian menerbitkan Surat Edaran Nomor 15 Tahun 2020 mengenai Pedoman Penyelenggaraan BDR yang menggunakan metode Pembelajaran Jarak Jauh (PJJ). PJJ ini sendiri telah diatur dalam Pemendikbud Nomor 24 Tahun 2012 dan mendefinisikan PJJ sebagai pendidikan yang peserta didiknya terpisah dari pendidik dan pembelajarannya menggunakan berbagai sumber belajar melalui teknologi informasi dan komunikasi, dan media lain.

PJJ untuk perguruan tinggi sendiri diatur dalam Permendikbud Nomor 109 Tahun 2013 yang mendefinisikan bahwa PJJ merupakan proses belajar-mengajar yang dilakukan secara jarak jauh dengan menggunakan berbagai media komunikasi. PJJ perguruan tinggi memiliki tujuan untuk memberikan layanan pendidikan tinggi kepada kelompok masyarakat yang tidak dapat mengikuti pendidikan secara tatap muka. Pada tahun 2016, Kementerian Riset, Teknologi, dan Pendidikan Tinggi (Kemenristekdikti) mencetuskan memanfaatkan Teknologi Informasi dan Komunikasi (TIK) dengan mengkombinasikan pembelajaran secara online dan tatap muka terpadu yang disebut juga dengan Blended Learnig.

Metode PJJ saat ini menjadi metode pembelajaran utama selama masa penanganan COVID-19. Metode ini tampaknya masih terasa baru bagi sebagian besar penyelenggara pendidikan. Banyak aspek yang perlu disesuaikan untuk tetap mencapai tujuan pendidikan yang telah ditetapkan oleh kurikulum. Perubahan metode pembelajaran ini juga terjadi begitu cepat dan drastis. Mahasiswa sebagai peserta didik yang menggunakan metode ini tidak memiliki banyak waktu untuk menyesuaikan diri dan dimungkinkan menemui berbagai kendala selama pelaksanaan PJJ. Mahasiswa yang biasa mengelola dan mengatur jadwal belajar sesuai kelas tatap muka harus meregulasi kembali jadwal belajarnya dengan metode PJJ. Regulasi diri dan jadwal belajar (selfregulation) dengan metode PJJ tentu saja berbeda dengan metode tatap muka. Ada perbedaan dalam cara interaksi antara mahasiswa dan dosen, serta metode penyampaian materi (Kuo, Walker, Schroder, \& Belland, 2014). Mahasiswa harus menyusun kembali strategi dalam regulasi belajar (self-regulated learning) secara online dengan memperhatikan berbagai aspek seperti lingkungan, keyakinan diri, tujuan belajar, dan sumber kekuatan diri.

Berdasarkan survei pendahuluan yang dilakukan peneliti mengenai kendala yang dialami selama kuliah dengan metode PJJ kepada 144 Mahasiswa, didapatkan hasil bahwa mahasiswa mengalami beragam kendala dalam pelaksanaan PJJ. Kendala yang ditemukan diantaranya: 1) Jaringan, sebesar 54,5\% mahasiswa yang berpartisipasi dalam studi pendahuluan menggunakan jaringan internet via telepon seluler, 44\% menggunakan Wifi, dan 1,5\% menggunakan keduanya. Mahasiswa yang menggunakan wifi mengeluhkan koneksi internet yang lebih lambat dari masa sebelum adanya COVID-19, sehingga mereka harus memiliki cadangan kuota melalui jaringan telepon seluler agar tetap dapat belajar. Sedangkan mereka yang menggunakan jaringan internet via telepon seluler mengeluhkan kendala tidak stabilnya jaringan dan banyaknya kuota yang harus dihabiskan karena mahasiswa harus mengakses berbagai platform pembelajaran online seperti Google Classroom, Zoom, maupun Microsoft Team dan hal ini terasa memberatkan mereka dan orang tua; 2) Iklim rumah/tempat tinggal, sejak metode PJJ diterapkan, 91,3\% Mahasiswa memilih untuk kembali ke rumah masing-masing dan melaksanakan PJJ dari rumah. 
Situasi belajar dari rumah tentu saja tidak lepas dari kendala seperti tidak kondusifnya situasi rumah untuk belajar. Terkadang mahasiswa harus berbagi penggunaan laptop atau alat belajar lainnya dengan saudara yang juga melaksanakan PJJ, harus tetap melaksanakan tugas-tugas rutinitas untuk merawat rumah meskipun sedang melaksanakan kelas online, situasi rumah yang ramai dan berisik, atau situasi lainnya yang cukup mengganggu konsentrasi selama mengikuti kelas online. Hal ini menunjukkan bahwa iklim belajar dari rumah tidak sekondusif pelaksanaan belajar tatap muka dan dapat mempengaruhi kualitas hasil belajar mereka; 3) Penggunaan laptop atau peralatan lainnya yang berlebihan, mahasiswa yang biasanya menerima materi langsung dan mencatat dibuku saat berada di kelas tatap muka, kini harus mengandalkan peralatan belajar seperti laptop maupun smartphone baik untuk mengikuti kelas online maupun untuk mengerjakan tugas. Hal ini membuat tidak adanya batasan waktu antara jam belajar dan jam istirahat. Tidak adanya batasan waktu belajar menimbulkan dampak seperti terganggunya waktu tidur di malam hari dan sering mengantuk atau tertidur saat kelas online diselenggarakan; 4) Tugas yang lebih banyak, mahasiswa juga harus menghadapi fakta bahwa dosen memberikan tugas yang lebih banyak dari biasanya karena tugas dianggap sebagai cara yang paling efektif untuk metode PJJ. Banyaknya tugas yang diberikan terkadang memiliki batas pengumpulan yang saling berdekatan ataupun waktu pengerjaan yang kadang dirasa tidak cukup sehingga mahasiswa kebingungan mana yang harus diprioritaskan terlebih dahulu; 5) Menurunnya motivasi belajar dan kejenuhan, mahasiswa merasakan adanya penurunan motivasi untuk mengikuti kelas online dari hari ke hari. Pada minggu-minggu awal, mereka merasa bersemangat untuk mengikuti kelas online, namun semakin menurun pada minggu-minggu berikutnya. Menurut mereka, jika biasanya pemahaman materi berada pada range 50\% - 80\% di kelas tatap muka, namun di kelas online mereka hanya memahami 30\%-50\% saja. Hal ini membuat mereka sangat mencemaskan hasil akhir belajar mereka karena merasa tidak mampu memahami materi seoptimal penyelenggaraan kelas tatap muka.

Kendala-kendala yang dialami mahasiswa di atas menunjukkan bahwa self-regulated learning sangat diperlukan untuk mengatur sistem BDR agar bisa mendapatkan hasil yang optimal seperti kelas tatap muka. Self-regulated learning berkaitan dengan bagaimana pelajar berusaha untuk membangun pengetahuan dengan secara metakognitif untuk memantau dan mengatur konten mental dan faktor-faktor di lingkungan eksternal. Objek pemantauan metakognitif meliputi kognisi, pengambilan keputusan, perencanaan, motivasi, pengaruh, dan emosi (Winne, 2015). Self-regulated learning juga fokus pada proses meningkatkan metode dan lingkungan suasana belajar (Zimmerman, 2015). Butuh self-regulated learning yang tinggi agar mahasiswa bisa mengelola kembali aktivitas belajar dan mengatasi berbagai hambatan yang muncul. Mahasiswa dianggap telah mencapai tingkat self-regulated learning yang memadai ketika mereka mampu secara sistematis menyesuaikan kinerja mereka dengan kondisi lingkungan dan pribadi yang berbeda (Zimmerman, 2000). Pada tingkat ini, siswa termotivasi oleh keyakinan diri (selfefficacy) mereka (Schunk \& DiBenedetto, 2015). Menurut Locke (1991), self-efficacy dan goal yang dimiliki merupakan variabel yang paling dekat sebagai prediktor kemampuan seseorang dalam menyelesaikan tugas.

Para peneliti menemukan bahwa self-efficacy memiliki pengaruh terhadap kemampuan belajar, motivasi dan self-regulation seseorang (Bandura, 1997; Pajares, 1996). Tidak hanya itu, selfefficacy juga sebagai penentu utama dalam motivasi, belajar, dan kemampuan self-regulation (Schunk \& DiBenedetto, 2015). Self-efficacy merupakan keyakinan seseorang mengenai kemampuan yang dimiliki (Bandura, 1986, Gaskill \& Hoy, 2002). Self-efficacy memainkan peran penting dalam pembelajaran yang dilaksanakan secara online (Joo, Bong, \& Choi, 2000; Alghamdia, Karpinskib, Leppb \& Barkleyc, 2020). Hasil penelitian menunjukkan bahwa self- 
efficacy berkorelasi positif dengan self-regulation. Siswa yang memiliki self-efficacy tinggi cenderung memiliki self-regulation yang baik. Mereka dapat menciptakan lingkungan yang efektif, menggunakan strategi belajar yang tepat, dan meminimalisir gangguan. Penelitian yang dilakukan oleh Pajares juga menunjukkan bahwa siswa yang memiliki self-efficacy tinggi akan kemampuan diri untuk belajar akan memberikan usaha lebih dan menyesuaikan performa mereka dibandingkan dengan mahasiswa dengan self-efficacy rendah. Mereka dengan self-efficacy rendah cenderung berpikir pesimis dengan kemampuan mereka untuk berkembang (Schwarzer, BaBler, Kwiatek \& Schroder, 1997). Saat siswa mengalami pemikiran yang negatif dan ketakutan akan kemampuan yang mereka miliki, seperti perasaan gugup saat akan menghadapi ujian, dapat menjadi pemicu menurunkan self-efficacy (dalam Schunk, et al., 2015).

Selama ini self-efficacy dikenal sebagai domain spesifik yang dibagi ke dalam beberapa aspek berdasarkan teori Bandura. Namun, beberapa peneliti membuat konsep self-efficacy lebih general (general self-efficacy) yang merujuk pada kepercayaan diri seseorang dalam menghadapai tuntutan pada berbagai situasi baru (Schwarzer et al., 1997). General self-efficacy dideskripsikan sebagai kepercayaan atas kompetensi seseorang dalam menghadapi berbagai tuntutan yang penuh tekanan atau tantangan dalam kehidupan (Schwarzer \& Jerusalem, 1995). General selfefficacy bertujuan untuk melihat kompetensi pribadi secara lebih luas dalam menangani berbagai situasi yang penuh tekanan secara efektif (Schwarzer et al., 1997; Zimmerman, 1995). Terdapat dua area interaksi antara pengembangan strategi self-regulated learning dengan pengembangan self-efficacy. Pertama, level self-efficacy memprediksi self-regulated learning, kemudian selfefficacy dan self-regulated learning sama-sama memprediksi prestasi akademik (Zimmerman, 1995; Gaskill, et al., 2002).

Seperti halnya self-efficacy, peran penting orientasi tujuan (goal orientation) mahasiswa dalam belajar menjadi salah satu fokus dalam pengelolaan self-regulated learning (Meece, Maehr \& Pintrich 1991; Wolters, Yu, \& Pintrich, 1996). Goal orientation menekankan pada pembahasan tujuan dan makna yang ditetapkan individu untuk keberhasilannya (Ames, 1992; Wolters, et al., 1996). Butler and Winne (1995) mengemukakan bahwa mahasiswa yang memiliki self-regulated learning dapat beradaptasi dengan kedua jenis goal orientation, baik mastery goal maupun performance goal. Saat mahasiswa fokus untuk meningkatkan pemahaman mereka, strategi selfregulation nya juga akan meningkat (Graham \& Golan 1991; Pintrich \& De Groot 1990; (Patrick, Ryan, \& Pintrich, 1999).

Dalam penelitian Lynch \& Dembo, (2004) menunjukkan bahwa terdapat hubungan positif antara self-efficacy dan self-regulated learning. Mahasiswa yang memiliki self-efficacy cenderung lebih termotivasi untuk lebih terikat dalam belajar dan menyelesaikan tugas-tugas akademik yang sulit (Alghamdia, et al., 2020). Beberapa penelitian menunjukkan bahwa menunjukkan mahasiswa perempuan memiliki self-efficacy yang lebih baik dibandingkan dengan laki-laki. Mahasiswa perempuan lebih yakin dalam mengelola kemampuan metakognitif nya dengan menerapkan berbagai strategi untuk mengelola kegiatan belajar dan tugas (Caprara et al., 2008; Alghamdia, et al., 2020). Begitu juga dengan self-regulated learning. Siswa perempuan menunjukkan lebih banyak kemampuan yang terkait dengan penetapan tujuan, perencanaan, dan pemantauan diri dibandingkan dengan siswa laki-laki (Zimmerman \& Martinez-Pons, 1990).

Berdasarkan fenomena yang muncul di atas, goal-orientation dan self-efficacy merupakan faktor yang memiliki peran penting dalam mengatur strategi belajar seseorang. Hanya saja, dimasa pembelajaran yang diselenggarakan dengan metode PJJ, banyak kendala yang dihadapi yang membuat mahasiswa harus meregulasi ulang kegiatan dan strategi belajar yang disesuaikan 
dengan kondisi PJJ dan lingkungannya. Banyak situasi yang berubah dan penyelenggaraan aktivitas belajar yang berbeda dengan metode tatap muka, sehingga mahasiswa perlu melakukan penyesuaian dengan kondisii baru ini. Oleh karena itu, penting untuk diteliti kembali pengaruh goal-orientation dan self-efficacy terhadap mahasiswa dalam meregulasi kegiatan belajarnya dengan metode belajar baru yaitu pembelajaran jarak jauh.

Apakah ada pengaruh goal orientation, general self-efficacy, dan jenis kelamin terhadap selfregulated larning dalam pembelajaran jarak jauh?

\section{METODE PENELITIAN}

Penelitian ini menggunakan metode kuantitatif. Sampel dalam penelitian ini merupakan mahasiswa Fakultas Pendidikan Psikologi Universitas Negeri Jakarta sebanyak 319 orang $(\mathrm{N}=319)$ yang sedang melaksanakan perkuliahan aktif dengan metode PJJ. Pengumpulan data dilakukan dengan metode skala dalam bentuk kuesioner online untuk menjangkau mahasiswa yang melaksanakan kuliah dari tempat tinggal masing-masing. Instrumen yang digunakan yaitu General Self-Efficacy Scale (Schwarzer \& Jerusalem, 1995) yang terdiri dari 10 butir pernyataan, $2 \times 2$ Achievement Goal Orientation Framework (Elliot \& McGregor, 2001) yang terdiri dari 12 butir pernyataan, dan Metacognitive Self-Regulation dalam Motivated Strategies Learning Questionaire (MSLQ) yang terdiri dari 12 butir penyataan. Uji validitas konstruk dilakukan dengan metode Confirmatory Factor Analysis (CFA). Analysis model diuji dengan menggunakan path analysis dengan memanfaatkan software MPlus Version 7.11 dari Muthen and Muthen (2013).

\section{HASIL DAN PEMBAHASAN}

Berdasarkan hasil uji path analysis diketahui chi-square $=2,39, d f=1, p$-value $=0,25>0,05)$, dan $R M S E A=0,067$. Indeks statistik tersebut menunjukkan model yang diuji fit dengan data karena telah memenuhi kriteria yang disyaratkan sebagai model fit. Diagram path analysis dapat dilihat pada gambar 1 .

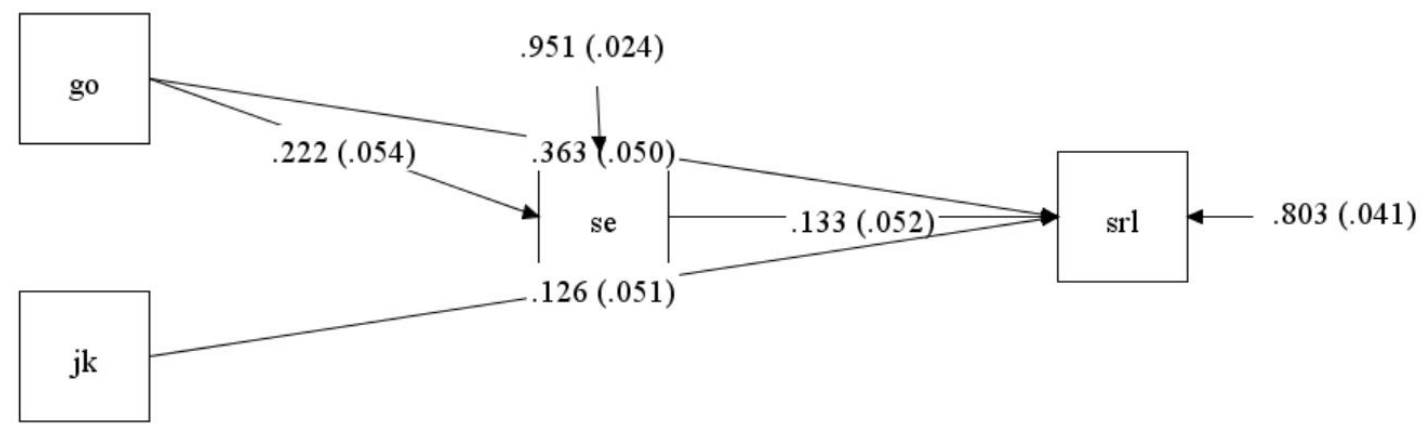

\section{Keterangan}

go = goal orientation, se = general self-efficacy, $j k=$ jenis kelamin, srl = self-regulated learning

Gambar 1. Diagram Path Analysis

Setelah model path analysis dinyatakan fit dengan data yang dimiliki, maka tahap selanjutnya adalah pengujian koefisien setiap variabel. 
Tabel 1. Koefisien Variabel

\begin{tabular}{lccccc}
\hline \multicolumn{1}{c}{ Variabel } & Coefficient & S.E. & T.Value & P.Value & Ket. \\
\hline \multicolumn{1}{l}{ Pengaruh langsung terhadap self-regulated learning } & & & & \\
\hline Goal Orientation & 0.363 & 0.050 & 7.295 & 0.000 & Signifikan \\
\hline General Self-Efficacy & 0.133 & 0.052 & 2.547 & 0.011 & Signifikan \\
\hline Jenis Kelamin & 0.126 & 0.051 & 2.456 & 0.014 & Signifikan \\
\hline
\end{tabular}

\begin{tabular}{lccccc} 
Pengaruh goal orientation terhadap self-regulated learning melalui mediator self-efficacy \\
\hline Goal Orientation & 0.222 & 0.054 & 4.091 & 0.000 & Signifikan \\
\hline
\end{tabular}

\begin{tabular}{ll} 
Fit Index & \\
\hline Chi-Square & 2.392 \\
\hline Root mean square approximation (RMSEA) & 0.067 \\
\hline Standardized Root Mean Squared Residual (SRMR) & 0.023 \\
\hline Comparative Fit Index (CFI) & 0.982 \\
\hline Tucker-Lewis Index (TLI) & 0.912 \\
\hline
\end{tabular}

Berdasarkan data pada tabel 1 dapat dilihat bawah keseluruhan jalur yang diujikan memiliki koefisien yang signifikan pada level signifikansi 0.05. Pengaruh langsung goal orientation terhadap self-regulated learning memiliki nilai koefisien tertinggi dalam penelitian ini, yaitu 0.363 (sig. 0.00). Nilai ini menunjukkan semakin tinggi goal orientation seseorang maka semakin tinggi pula self-regulated learning yang dimiliki. Sedangkan pengaruh jenis kelamin terhadap self-regulated learning memiliki nilai koefisien terendah, yaitu 0.126 (sig. 0.014). Dalam proses coding, mahasiswa laki-laki diberi kode 0 dan mahasiswa diberi kode 1 . Nilai pengaruh jenis kelamin terhadap self-regulated learning bernilai positif. Artinya, self-regulated learning pada mahasiswa perempuan lebih tinggi dari pada self-regulated learning pada mahasiswa laki-laki.

Goal orientation memiliki pengaruh langsung sebesar 0.363 terhadap self-regulated learning. Nilai ini berpengaruh positif yang menunjukkan semakin tinggi goal orientation maka semakin tinggi pula self-regulated learning yang dimiliki mahasiswa. Demikian juga general self-efficacy dan jenis kelamin yang memiliki pengaruh langsung terhadap self-regulated learning. Goal orientation juga memiliki pengaruh tidak langsung terhadap self-regulated learning melalui mediator oleh general self-efficacy. Dengan demikian, dapat disimpulkan hipotesis penelitian bahwa terdapat pengaruh signifikan goal orientation, general self-efficacy, dan jenis kelamin terhadap self-regulated learning dan terdapat pengaruh signifikan goal orientation, terhadap selfregulated learning dengan mediator general self-efficacy.

Tabel 2. R-Square Variabel

\begin{tabular}{lccccc}
\hline Variabel & Coefficient & S.E. & T.Value & P.Value & Ket. \\
\hline go se jk $\rightarrow$ srl & 0.197 & 0.041 & 4.805 & 0.000 & Signifikan \\
\hline go $\rightarrow$ se & 0.049 & 0.024 & 2.045 & 0.041 & Signifikan \\
\hline
\end{tabular}

Data pada tabel 2 menunjukkan variable goal orientation, general self-efficacy, dan jenis kelamin menyumbangkan pengaruh sebesar 0.197 atau $19.7 \%$ terhadap self-regulated learning. Sedangkan goal orientation menyumbang pengaruh sebesar 0.049 atau 4,9\% terhadap general self-efficacy sebagai variable mediator. Data uji path analysis dalam penelitian ini menunjukkan keseluruhan variable memberikan efek pengaruh terhadap self-regulated learning pada mahasiswa selama melaksanakan Belajar Dari Rumah dengan metode Pembelajaran Jarak Jauh dengan nilai koefisien yang tidak terlalu besar. 
Berdasarkan hasil penelitian yang telah dipaparkan ditemukan bahwa goal orientation, selfefficacy dan jenis kelamin memiliki pengaruh terhadap self-regulated learning. Goal orientation memiliki peran yang cukup penting dalam membantu mahasiswa meregulasi kembali aktivitas akademik yang saat ini berlangsung dengan metode PJJ. Mahasiswa yang memiliki goal orientation yang jelas dimungkinkan untuk lebih mampu pengelolaan dan pengaturan aktivitas dengan lebih baik. Berdasarkan teori, baik mastery goal maupun performance goal dapat menguatkan self-regulated learning dan mahasiswa yang memiliki self-regulated learning yang baik dapat beradaptasi dengan kedua jenis goal orientation tersebut (Butler \& Winne, 1995). Saat mahasiswa fokus untuk meningkatkan pemahaman mereka dalam belajar, maka strategi self-regulation nya juga akan meningkat (Graham \& Golan 1991; Pintrich \& De Groot 1990; Patrick, Ryan, \& Pintrich, 1999).

Begitu pula dengan self-efficacy yang merupakan salah satu faktor yang dapat membantu mahasiswa untuk lebih baik dalam mengatur strategi belajar mereka selama mengikuti PJJ. Mahasiswa yang optimis dengan kemampuan yang dimiliki cenderung memiliki strategi diri yang lebih baik dalam mengelola aktivitas belajar selama PJJ dibandingkan dengan mereka yang tidak begitu yakin dengan kemampuan dirinya. Mahasiswa yang lebih terikat dalam belajar dan termotivasi untuk menyelesaikan tugas-tugas sulit lebih dimungkinkan memiliki self-regulated learning yang lebih baik karena ia meyakini bahwa mereka memiliki kemampuan untuk mengelola kegiatan belajar.

Koefisien pengaruh jenis kelamin terhadap self-regulated learning menunjukkan nilai positif. Hasil ini mengemukakan bahwa self-regulated learning pada mahasiswa perempuan lebih tinggi daripada self-regulated learning pada mahasiswa laki-laki. Hasil ini mengindikasikan bahwa mahasiswa perempuan jauh lebih mampu dalam menyusun strategi belajar yang efektif dan mampu mengelola aktivitas belajar dengan lebih baik dibandingkan mahasiswa laki-laki. Hasil ini sejalan dengan penelitian terdahulu yang mengungkapkan bahwa perempuan menunjukkan lebih banyak kemampuan yang terkait dengan penetapan tujuan, perencanaan, dan pemantauan diri dibandingkan dengan siswa laki-laki (Zimmerman \& Martinez-Pons, 1990).

Selain memiliki pengaruh langsung, goal orientation juga memiliki pengaruh tidak langsung terhadap self-regulated learning dengan mediator self-efficacy. Goal orientation memengaruhi self-efficacy yang kemudian memengaruhi self-regulated learning mahasiswa. Hal ini menunjukkan bahwa mahasiswa yang memiliki tujuan belajar yang jelas cenderung memiliki self-efficacy yang lebih tinggi dimana hal ini memengaruhi pula strategi mereka dalam meningkatkan self-regulated learning selama PJJ. Adanya pengaruh tidak langsung ini mengindikasikan bahwa untuk meningkatkan self-regulated learning mahasiswa dapat meningkatkan self-efficacy dengan menetapkan tujuan yang jelas saat menghadapi segala kendala yang muncul selama melaksanakan kuliah dengan metode PJJ.

Data uji path analysis ini mengemukakan bahwa kendala-kendala yang dialami oleh mahasiswa selama melakukan pembelajaran jarak jauh dapat diminimalisir dengan meningkatkan keyakinan diri terhadap kemampuan yang dimiliki dan penetapan tujuan belajar yang jelas, sehingga mampu menetapkan strategi yang tepat untuk mengelola dan mengatur aktivitas belajar supaya kualitas belajar tetap sama dengan pelaksanaan belajar secara tatap muka. Mahasiswa harus mampu menetapkan tujuan belajar yang jelas baik secara mastery goal maupun performance goal, sehingga setiap kendala yang muncul memiliki pedoman penyelesaian yang jelas pula sesuai tujuan yang telah ditetapkan. 


\section{KESIMPULAN DAN SARAN}

Berdasarkan hasil penelitian yang telah dipaparkan ditemukan bahwa terdapat pengaruh signifikan goal orientation, general self-efficacy, dan jenis kelamin terhadap self-regulated learning dan terdapat pengaruh signifikan goal orientation terhadap self-regulated learning dengan mediator general self-efficacy. Data juga mengungkapkan bahwa self-regulated learning mahasiswa perempuan lebih tinggi dari pada mahasiswa laki-laki. Hasil penelitian ini sejalan dengan berbagai hasil penelitian yang telah dilakukan oleh berbagai peneliti sebelumnya. Dengan demikian, mahasiswa diharapkan dapat mengatasi kendala-kendala mereka selama melaksanakan aktivitas perkuliahan menggunakan metode PJJ dengan menetapkan tujuan belajar yang jelas dan meningkatkan keyakinan akan kemampuan yang dimiliki, sehingga dapat merumuskan strategi belajar yang tepat dan efektif sesuai kemampuan diri.

Penelitian memiliki fokus bahasan untuk faktor-faktor yang dapat memengaruhi strategi pengelolaan belajar mahasiswa dalam masa penyesuaian diri dengan metode pembelajaran jarak jauh yang merupakan dampak dari adanya pandemik COVID-19 di Indonesia mulai awal Maret 2020. Penelitian ini mengaitkan dengan faktor goal orientation dan self-efficacy untuk melihat self-regulated learning mahasiswa. Penelitian ini diharapkan dapat memberikan masukan yang berarti bagi mahasiswa maupun institusi penyelenggara pendidikan agar dapat memanfaatkan goal orientation dan self-efficacy yang dimiliki mahasiswa agar dapat mengatasi kesulitan dalam mengelola aktivitas belajar dengan lebih efektif.

Selama penelitian dilaksanakan disadari bahwa banyak faktor dan variabel lain yang dimungkinkan memberikan kontribusi terhadap self-regulated learning mahasiswa selama menyesuaikan diri dengan metode PJJ. Dengan diperpanjangnya masa belajar dari rumah oleh pemerintah, maka topik ini masih sangat menarik untuk diangkat oleh peneliti lainnya mengingat banyaknya fenomena-fenomena baru yang muncul pada kalangan mahasiswa saat melaksanakan pembelajaran jarak jauh. Namun, hendaknya peneliti berikutnya dapat menggunakan faktor lainnya dengan model yang berbeda, sehingga hasil penelitian dapat memberikan kontribusi dari sudut pandang yang berbeda pula agar dapat membantu mahasiswa mengatasi kesulitan belajar selama PJJ dan menemukan strategi yang tepat dalam mengelola aktivitas belajar. Memperluas jangkauan populasi dan sampel yang diambil juga dianjurkan dapat dilakukan oleh peneliti selanjutnya agar generalisasi hasil penelitian lebih luas dan memiliki manfaat yang lebih luas pula.

\section{Ucapan Terima Kasih (Acknowledgement)}

Selama penelitian dilaksanakan, banyak pihak yang telah membantu hingga peneliti dapat merumuskan artikel ini. Peneliti mengucapkan banyak terima kasih kepada mahasiswa yang telah bersedia menjadi partisipan penelitian dan mengisi dengan sungguh-sungguh. Terima kasih juga disampaikan untuk dosen yang telah bersedia membantu peneliti dalam menyebarkan kuesioner penelitian, sehingga terkumpul data yang diperlukan. Terima kasih pula disampaikan kepada Ibu Nia Tresniasari, M.Si yang telah mengarahkan peneliti dalam pengolahan data dan memberikan banyak masukan dalam merumuskan hasil penelitian. Ucapan terima kasih juga disampaikan kepada pihak-pihak lainnya yang telah membantu penelitian ini dan tidak dapat disebut satu persatu. 


\section{REFERENSI}

Alghamdi, A., Karpinski, A. C., Lepp, A., \& Barkley, J. (2020). Online and face-to-face classroom multitasking and academic performance: Moderated mediation with selfefficacy for self-regulated learning and gender. Computers in Human Behavior, 102, 214-222.

Ames, C. (1992). Classrooms: goals, structures, and student motivation. Journal of Educutional Psychology, 84, 261-271.

Bandura, A. (1986). Social foundations of thought and action: a social cognitive theory. Englewood Cliffs, NJ: Prentice - Hall.

Bandura, A. (1997). Self-efficacy: the exercise of control. New York: W. H. Freeman and Company.

Butler, D., \& Winne, I. (1995). Feedback and self-regulated learning: a theoretical synthesis. Review of Educational Research, 65, 245-281.

Caprara, G. V., Fida, R., Vecchione, M., Del Bove, G., Vecchio, G. M., Barbaranelli, C., \& Bandura. A. (2008). Longitudinal analysis of the role of perceived self-efficacy for selfregulated learning in academic continuance and achievement. Journal of Educational Psychology, 100(3), 525.

Elliot, A. J., \& McGregor, H. A. (2001). A 2 x 2 achievement goal framework. Journal of Personality and Social Psychology, 80(3), 501-519.

Gaskill, P. J., \& Hoy, A. W. (2002). Self-efficacy and self-regulated learning: the dynamic duo in school performance. Improving academic achievement, 9, 185-207.

Graham, S. \& Golan, S. (1991). Motivational influences on cognition: task involvement, ego involvement, and depth of information processing. Journal of Educational Psychology, 83,187-194.

Joo, Y. J., Bong, M., \& Choi, H. J. (2000). Self-efficacy for self-regulated learning, academic self-efficacy, and Internet self-efficacy in web-based instruction. Educational Technology Research \& Development, 48(2), 5-17.

Kuo, Y., Walker, A.E., Schroder, K.E.E., \& Belland, B. R. (2014). Interaction, Internet selfefficacy, and self-regulated learning as predictors of student satisfaction in online education courses. Internet and Higher Education, 20, 35-50.

Locke, E. A. (1991). The motivation sequence, the motivation hub, and the motivation core. Organizational Behavior and Human Decision Processes, 50, 288-299.

Lynch, R., \& Dembo, M. (2004). The relationship between self-regulation and online learning in a blended learning context. International Review of Research in Open and Distance Learning, 5(2).

Meece, J. L. (1991). The classroom context and student motivational goals. In M. L. Maehr \& P. R. Pintrich (Eds.) Advances In Motivation And Achievement. (Vol. 7, pp. 261-285) Greenwich. CT: JAI Press.

Pajares, F. (1996). Self-efficacy beliefs in achievement settings. Review of Educational Research, 66, 543-578

Patrick, H., Ryan, A. M., \& Pintrich, P. R. (1999). The differential impact of extrinsic and mastery goal orientation on males' and females' self-regulated learning. Learning and Individual Differences. 11(2), 153-171.

Peraturan Menteri Pendidikan dan Kebudayaan Republik Indonesia, Nomor 109 Tahun 2013, tentang Penyelenggaraan Pendidikan Jarak Jauh pada Pendidikan Tinggi.

Peraturan Menteri Pendidikan dan Kebudayaan Republik Indonesia, Nomor 24 Tahun 2012, tentang Penyelenggaraan Pendidikan Jarak Jauh pada Pendidikan Tinggi

Pintrich, P. R., \& E. V. De Groot. (1990). Motivational and self-regulated learning components of classroom academic performance. Journal of Educational Psychology, 82,334O. 
Pintrich, P. R., Smith, D. A. F., Garcia, T., \& McKeachie, W. J. (1991). A manual for the use of the motivated strategies for learning questionnaire (MSLQ). The University of Michigan.

Schunk, D. H., \& DiBenedetto, M. K. (2015). Self-efficacy: Education aspects. International Encyclopedia of the Social \& Behavioral Sciences, $\left(2^{\text {nd }}\right)$ 21, 515-521.

Schwarzer, R., \& Jerusalem, M. (1995). Generalized self--efficacy scale. In J. Weinman, S. Wright, \&M. Johnston, Measures in health psychology: A user's portfolio. Causal andcontrol beliefs (pp. 35--37).

Schwarzer, R., Babler, J., Kwiatek, P., \& Schroder, K. (1997). The assessment of optimistic selfbeliefs: comparison of the German, Spanish, and Chinese versions of the general selfefficacy scale. Applied Psychology: An International Review, 46(1), 69-88.

Surat Edaran Kementerian Pendidikan dan Kebudayaan Republik Indonesia, Nomor 04 Tahun 2020, tentang Pelaksanaan Kebijakan Pendidikan dalam Masa Darurat Penyebaran Coronavirus Disease (Covid 19).

Surat Edaran Kementerian Pendidikan dan Kebudayaan Republik Indonesia, Nomor 15 Tahun 2020, tentang Pedoman Masa Darurat Penyebaran Coronavirus Disease (Covid 19).

Winne, P. H. (2015). Self-regulated learning. International Encyclopedia of the Social \& Behavioral Sciences, $\left(2^{\text {nd }}\right)$ 21, 535-540.

Wolters, C. A., Yu, S. L., \& Pintrich, P. R. (1996). The relation between goal orientation and student's motivational beliefs and self-regulated learning. Learning and Individual Differences, 8(3), 211-238.

Zimmerman, B. J. (2015). Self-regulated learning: Theories, measures, and outcomes. International Encyclopedia of the Social \& Behavioral Sciences $\left(2^{\text {nd }}\right) 21,541-546$.

Zimmerman, B. J. (2000). Attaining self-regulation: a social cognitive perspective. In Handbook of Self-regulation. Academic Press, San Diego, 13-39.

Zimmerman, B. J., \& Martinez-Pons, M. (1990). Student differences in self-regulated learning: Relating grade, sex, and giftedness to self-efficacy and strategy use. Journal of Educational Psychology, 82(1), 51. 